\title{
Development of an Improved Isocratic HPLC Method for the Determination of Gallic Acid, Caffeine and Catechins in Tea
}

\author{
SM Kingori ${ }^{1 *}$, PO Ongoma ${ }^{2}$ and SO Ochanda ${ }^{1}$ \\ ${ }^{1}$ Kalro- Tea Research Institute, P.o Box 820-20200, Kericho, Kenya \\ ${ }^{2}$ Department of Chemistry, Egerton University, Po Box 536-20115 Egerton, Kenya
}

Received: April 04, 2018; Accepted: June 06, 2018; Published: June 25, 2018

*Corresponding author: Kalro- Tea Research Institute, P.o Box 820-20200, Kericho, Kenya, Tel: +254721900104 E-Mail: smkingori@gmail.com

\begin{abstract}
A simple and sensitive reversed phase high performance liquid chromatographic (HPLC) method was developed for the determination of biomolecules in different types of tea. Most of the High Performance Liquid Chromatography (HPLC) methods used for the determination of tea biochemicals include gradient elution systems which involve expensive instrumentation. The aim of this study was to develop an improved sensitive, fast, cost effective and accurate isocratic HPLC method with photo diode array (PDA) detection for analysis of Gallic acid, caffeine and catechins in tea, using a suitable internal standard. The developed HPLC analytical method consisted of a $\mathrm{C}_{6}$ phenyl column and an isocratic elution system of Water: acetonitrile: methanol: ortho phosphoric acid: ethyl acetate (77.5:18:2.0:0.5:2.0 $\mathrm{v} / \mathrm{v} / \mathrm{v} / \mathrm{v} / \mathrm{v}$ ) at a flow rate of $1.0 \mathrm{~mL} / \mathrm{min}$. The detection wavelength was chosen at $278 \mathrm{~nm}$ with guaiacol (2-methoxyphenol) used as an internal standard as it did not co-elute with the analytes of interest. Statistical comparison of the analytical result obtained for gallic acid, caffeine and catechins in four tea types - green CTC (cut, tear and curl), black CTC, green orthodox and black orthodox using the developed method and ISO 1405-2:2005(E) method did not show significant difference. The method was validated and showed consistency to qualitative and quantitative determination of the tea biomolecules of interest.
\end{abstract}

\section{Introduction}

Tea (Camellia sinensis) is a beverage consumed for refreshment and health benefits since ancient times [27]. Tea has been consumed for various reasons including its antioxidant properties sensory properties and potential health benefits [2, $5,16,18,26]$. It is the second most consumed beverage in the world after water and is commonly served hot or iced [20]. Tea is produced mostly from the two tender leaves and a bud of the plant. Studies have shown that tea provides several health benefits, such as reduction of cholesterol, obesity, protection against cardiovascular disease and cancer $[7,21]$. Tea is a unique beverage with biomolecules whose chemical compositions can be used as indicators of the quality of tea $[9,31]$. Levels of these chemicals are directly proportional to quality indicators both in aerated and non-aerated tea products [25]. Therefore, there is need to explore easy scientific techniques of determining quality parameters with an aim of complimenting the subjective organoleptic evaluation techniques commonly used in the tea industry.

Catechins are the primary polyphenols in tea and account for $75-80 \%$ of the soluble ingredients $[24,28]$. They are powerful antioxidants that provide several benefits [23]. Gallic acid and caffeine are also found in both aerated and non-aerated CTC and orthodox teas $[15,19]$. Figure 1 shows biomolecules of interest in this study found in tea.

High performance liquid chromatography (HPLC) methods have been developed to separate, identify and quantify gallic acid, caffeine and catechins present in tea. The methods are mostly gradient elution systems [12, 22, 30]. However, gradient elution compared to isocratic systems, requires expensive instrumentation and computerized processors [11]. It is also difficult to optimize the operating conditions and obtain reproducible results [32]. Moreover, some isocratic methods studied using $\mathrm{C}_{18}$ (ODS stationary phase) column are also irreproducible, have poor resolution and low chromatographic efficiency especially under methanol based mobile phases [6, 29].

Due to variability in the compositions of tea catechins, caffeine and gallic acid and their potential health benefits, it is important to establish a simple and reliable analytical method for the determination of these compounds. The current method is simple as it involves a less complex isocratic system and can be used in common laboratories having low cost HPLC machines. The method can be used to determine quality parameters of tea, levels of tea biomolecules in tea value added products especially tea based supplements and estimation of levels of adulteration of tea in the local market.

\section{Material and Methods \\ Tea Samples for Analysis}

Non- aerated green, aerated black CTC teas and orthodox non - aerated, orthodox aerated black teas were sourced in triplicate from Kangaita tea factory of Kirinyaga County in Kenya. 
<smiles>Oc1cc(O)c2c(c1)OC(c1ccc(O)c(O)c1)[C@H](O)C[C@@H]2Oc1cc(O)c2c(c1)O[C@H](c1ccc(O)c(O[Hg]c3cc(O)c4c(c3)O[C@H](c3cc(O)c(O)c(O)c3)[C@H](O)C4)c1)[C@H](O)C2</smiles>

(a)

(b)

(c)<smiles>O=C(OC1Cc2c(O)cc(O)cc2O[C@H]1c1cc(O)c(O)c(O)c1)c1cc(O)c(O)c(O)c1</smiles>

(d)<smiles>O=C(O)c1cc(O)c(O)c(O)c1</smiles>

(e)<smiles>Cn1c(=O)c2c(ncn2C)n(C)c1=O</smiles>

(f)<smiles>O=C(O[C@H]1Cc2c(O)cc(O)cc2O[C@H]1c1ccc(O)c(O)c1)c1cc(O)c(O)c(O)c1</smiles>

(g)

Figure 1: Chemical Structures of the major tea catechins, gallic acid and caffeine: (a) (+) Catechin, (b) (-) Epicatechin, (c) (-) Epigallocatechin, (d)(-) Epigallocatechingallate, (e) Gallic acid, (f) Caffeine, (g)(-) Epicatechingallate

\section{Reagent and Chemicals}

All standards viz. gallic acid (GA), epigallocatechin (EGC), $(+)$-catechin $(+C),(-)$ - epigallocatechin (EC), (-)-epigallocatechin gallate (EGCG), ( - )- epicatechin gallate (ECG), caffeine, 3-fluorocatechol, guaiacol (2-methoxyphenol), 4-methylcatecol and EDTA were purchased from Sigma Chemical Co., US. Acetonitrile, methanol, glacial acetic acid (both HPLC grade), ethyl acetate, methanoic acid, ortho-phosphoric acid and acetone were purchased from Finar India Ltd. All solvents were degassed and filtered through a $0.45 \mu \mathrm{m}$ filter (Millipore filter No. HAWP04700).

\section{HPLC Instrumentation and Conditions}

The HPLC system Shimadzu LC 20A series consisted of binary pump with vacuum degasser (DGU-20A ${ }_{5 \mathrm{R}}$ ), thermostated column compartment (CTO-10AS vp), auto sampler (SIL $20 \mathrm{AT}_{\mathrm{HT}}$ ), diode array detector (SPD-20 MA) all from Shimadzu Corporation, Japan. $\mathrm{C}_{6}$-phenyl reversed-phase column $(4.6 \times 250 \mathrm{~mm}, 5 \mu)$ was used and the column temperature was maintained at $35^{\circ} \mathrm{C}$. A suitable mobile phase was investigated from the following matrix combinations.

1. Water: methanol: acetic acid: EDTA

2. Water: methanol: Ortho- phosphoric acid: EDTA

3. Water: acetonitrile: methanol: acetic acid: ethyl acetate

4. Water: acetonitrile: methanol: Ortho- phosphoric acid: ethyl acetate 
5. Methanol:water:methanoic acid

6. Acetonitrile:water: methanoic acid

7. Acetonitrile:water:methanol:acetic acid

8. Water:methanol:ethyl acetate

9. Methanol:EDTA:water

10. Acetic acid :acetone:water

11. Water: acetonitrile: acetic acid: EDTA; starting with $(0: 100: 0.1 \% \mathrm{v} / \mathrm{v} / \mathrm{v})$ and increasing stepwise by $10 \%$; e.g. Methanol:water:methanoic acid (100:0:0.1\% v/v/v).

\section{Preparation of Stabilizing Solution}

A solution of $25 \mathrm{ml}$ of EDTA $(10 \mathrm{mg} / \mathrm{ml}), 25 \mathrm{ml}$ ascorbic $(10 \mathrm{mg} / \mathrm{ml})$ acid solution and $50 \mathrm{ml}$ acetonitrile (HPLC grade) was transferred to a $500 \mathrm{ml}$ one-mark volumetric flask, diluted to the mark with distilled water and mixed.

\section{Preparation of Standard Solution}

Stock solutions of the standards -GA, EGC, +C, EC, EGCG, ECG, caffeine and guaiacol (2-methoxyphenol) were prepared at 1000 $\mu \mathrm{g} / \mathrm{ml}$ by dissolving in the stabilizing solution, gently warming if necessary ( $\max .40^{\circ} \mathrm{C}$ ) and then cooling to room temperature $\left(20-25^{\circ} \mathrm{C}\right)$. Five different concentration mixtures, 2- $1000 \mu \mathrm{g} /$ $\mathrm{ml}$ of each of the standards were diluted from the standard stock solutions and passed through $0.45 \mu \mathrm{m}$ Millipore filter before injecting into HPLC. Standard curves for the standards were plotted. Peak area responses were obtained for each of the standards relative to the peak area of guaiacol (2-methoxyphenol).

\section{Preparation of Samples}

Finely milled tea test samples were weighed $(0.200 \pm 0.001)$ $\mathrm{g}$ into extraction tubes. The extraction tubes containing the sample were placed in a water bath set at $70^{\circ} \mathrm{C}$ and $5.0 \mathrm{ml}$ of hot methanol/water $(7: 3 \mathrm{v} / \mathrm{v})$ extraction mixture was dispensed. The extraction tubes were stoppered and mixing done with the help of a vortex mixer. The heating of the extraction tubes in the water bath continued for $10 \mathrm{~min}$, mixing on the vortex mixer after 5 min and $10 \mathrm{~min}$. The extraction tubes from the water bath were removed and allowed to cool to room temperature. The stoppers were removed and the tubes placed in a centrifuge at 3500 rpm for $10 \mathrm{~min}$. The supernatant was carefully decanted into a graduated tube. The extraction steps were repeated resulting in two extracts. The two extracts were combined and made to 10 $\mathrm{ml}$ with cold methanol/water extraction mixture. On mixing, the extract was allowed to attain room temperature $\left(20-25^{\circ} \mathrm{C}\right)$ before carrying out the assay.

\section{Method Validation}

Method for quantitative and qualitative analysis of GA, $(-)$-EGC, caffeine, (+)-C, (-) -EC, (-) -EGCG and (-) - ECG was validated for its specificity, linearity, accuracy, level of detection (LOD), level of quantitation (LOQ) and precision by utilization the Food and Drug Administration (FDA) guidelines [10].

\section{Results and Discussion}

\section{Optimization of Chromatographic Conditions}

A simple, sensitive, fast, cost effective and accurate isocratic HPLC method with diode array detection for analysis of gallic acid, caffeine and catechins in tea, using a suitable internal standard was developed. The method consisted of the use of a $\mathrm{C}_{6}$-phenyl column which combines low adsorption ability of the hexyl spacer for less polar groups and strong $\pi-\pi$ interactions between the phenyl group and the substrate (polyphenols) via dipole- dipole and dipole-induced dipole forces to enhance its performance [4].

A comprehensive study was systematically carried out to determine the best mobile phase combination for the method as shown in table 1.

Table 1: Isocratic elution systems investigated for separation of gallic acid, caffeine and catechins in tea at $35{ }^{\circ} \mathrm{C}$

\begin{tabular}{|c|c|c|c|}
\hline System & Matrix composition & Matrix ratio (v/v) & Runtime (min) \\
\hline A & Water: methanol: acetic acid: EDTA $(20 \mu \mathrm{g} / \mathrm{ml})$ & 80:19.3:0.5:0.2 & 60 \\
\hline $\mathrm{B}$ & Water: methanol: Ortho phosphoric acid (50\%): EDTA & $79.3: 20: 0.5: 0.2(20 \mu \mathrm{g} / \mathrm{ml})$ & 60 \\
\hline $\mathrm{C}$ & Water: acetonitrile: methanol: acetic acid: ethyl acetate & $77.5: 18: 2.0: 0.5: 2.0$ & 12.5 \\
\hline $\mathrm{D}$ & $\begin{array}{l}\text { Water: acetonitrile: methanol :Ortho phosphoric acid ethyl } \\
\text { acetate }\end{array}$ & $77.5: 18: 2.0: 0.5: 2.0$ & 12.5 \\
\hline $\mathrm{E}$ & Water: methanol: methanoic acid & $79.5: 20: 2.0: 0.5$ & 60 \\
\hline $\mathrm{F}$ & Water: acetonitrile: methanoic acid & $79.5: 20: 0.5$ & 50 \\
\hline $\mathrm{G}$ & Water: acetonitrile: methanol: acetic acid & $79.5: 18: 2.0: 0.5$ & 14.5 \\
\hline $\mathrm{H}$ & Water: methanol: ethyl acetate & $85: 10: 5$ & 40 \\
\hline I & Water: methanol: EDTA $(20 \mu \mathrm{g} / \mathrm{ml})$ & 79:20:01 & 60 \\
\hline $\mathrm{K}$ & Water: acetonitrile: acetic acid: EDTA $(20 \mu \mathrm{g} / \mathrm{ml})$ & 86.3:13:0.5:0.5:0.2 & 45 \\
\hline
\end{tabular}


Finally, a mobile phase containing water: acetonitrile: methanol:Orth-phosphoricacid:ethylacetate (77.5:18:2.0:0.5:2.0) was adapted for use in the method (figure2). The mobile phase flow rate was $1.0 \mathrm{~mL} /$ minute and the injection volume $20 \mu \mathrm{L}$. The separations were performed at $35^{\circ} \mathrm{C}$, absorption measured at $278 \mathrm{~nm}$, with the compounds of interest effectively detected and separated. Saito, et al. 2006 worked with a similar mobile phase matrix composition using acetic acid and incorporating both isocratic and time gradient conditions in their method. The total run time was 37 minutes, when flow rate gradient was introduced, all the components were eluted within 27 minutes. Additionally, only caffeine and three catechins (EGCG, EC and $+C$ ) were reported to have been determined [29]. The systems of the developed method can elute the components of interest in less than 10 minutes and both qualitative and quantitative determinations have yielded success. With the inclusion of the internal standard of interest and an allowance of a short wash time total analysis time can be achieved in $12.5 \mathrm{~min}$ as shown in figure 2 . The mobile phase composition of the developed method uses low $\mathrm{pH}(2-3)$, these is necessary as catechins are unstable in basic solutions and can bind to various metals especially calcium, magnesium, iron, zinc as well as trace levels other minerals that could react with the catechins $[3,14]$. Addition of very small amount of ethyl acetate increased resolution efficiency especially for the closely eluting peaks of caffeine and EGC [13]. Also, being a chelating agent helped to prevent the decomposition of the catechins by binding with trace ions in the chromatographic system [1].

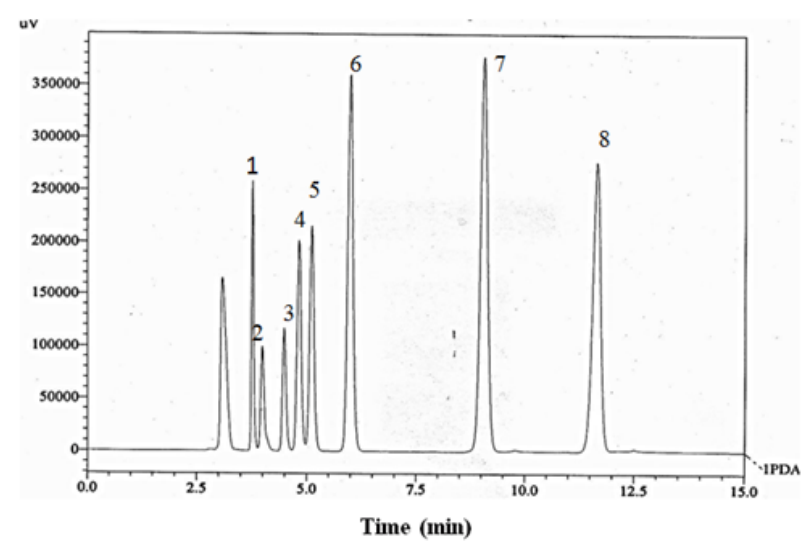

Figure 2: HPLC chromatogram of mixed standards at $278 \mathrm{~nm}$. Peaks: 1-gallic acid (GA); 2- (-) epigallocatechin (EGC); 3-caffeine (CA), 4- (+) catechin $(+C)$, 5- $(-)$ epicatechin (EC); 6- $(-)$ epigallocatechin gallate (EGCG); 7-(-) epicatechin gallate (ECG), 8-internal standard guaiacol (2methoxyphenol)

The choice of a suitable internal standard was investigated amongst 3-fluorocatechol, guaiacol (2-methoxyphenol), and 4-methylcatecol as they are phenols. Guaiacol (2-methoxyphenol) was a good internal standard for the method as it showed no coelution with the analytes (figure 2) and gave good quantitation levels for gallic acid, caffeine and the major catechins. Figure 3 and figure 4 shows HPLC chromatograms of nonaerated green CTC tea before and after being spiked with the internal standard guaiacol (2- methoxyphenol) respectively and further demonstrates that the internal standard does not coelute with components in sample matrix. HPLC chromatogram for aerated black CTC also showed similar result figure 5 and figure 6 .

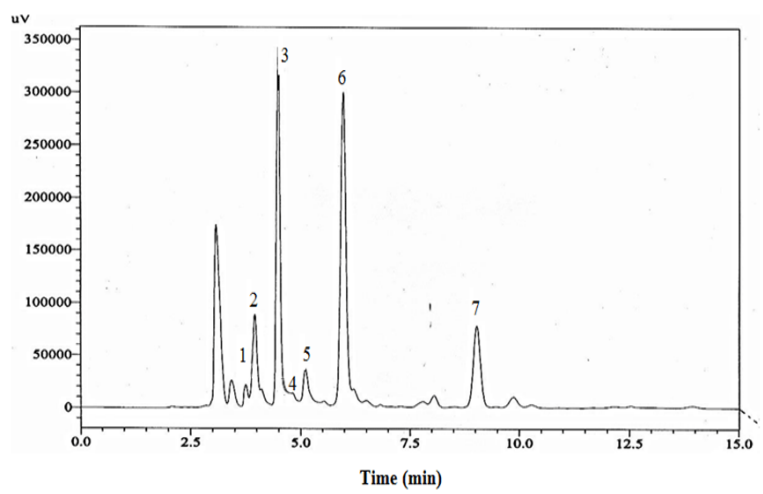

Figure 3: HPLC chromatogram of non-aerated green CTC tea at $278 \mathrm{~nm}$. Peaks: 1- gallic acid (GA); 2 - (-) epigallocatechin (EGC); 3 - caffeine (CA), 4 - (+) catechin (+C), 5 - (-) epicatechin (EC); 6-(-) epigallocatechin gallate (EGCG); 7 - (-) epicatechin gallate (ECG)

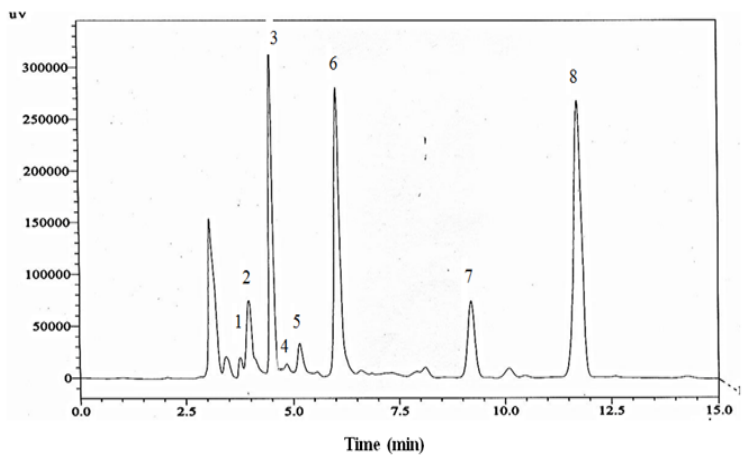

Figure 4: HPLC chromatogram of non-aerated green CTC tea at $278 \mathrm{~nm}$ spiked internal standard guaiacol (2- methoxyphenol). Peaks: 1- gallic acid (GA); 2- (-) epigallocatechin (EGC); 3 - caffeine (CA), 4- (+) catechin $(+C)$, 5- (-) epicatechin (EC); 6- (-) epigallocatechin gallate (EGCG); 7- (-) epicatechin gallate (ECG), 8 - guaiacol (2- methoxyphenol)

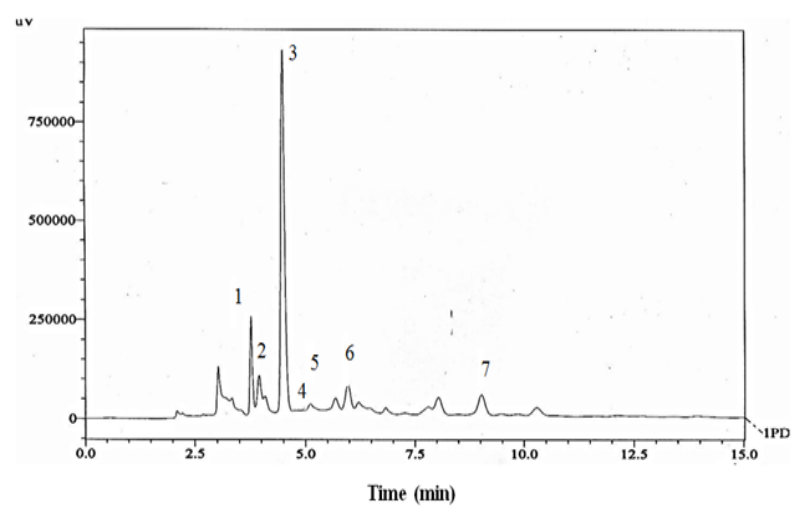

Figure 5: HPLC chromatogram of aerated black CTC at $278 \mathrm{~nm}$. Peaks: 1- gallic acid (GA); $2-(-)$ epigallocatechin (EGC); 3- caffeine (CA), 4- (+) catechin $(+C)$, 5- $(-)$ epicatechin $(\mathrm{EC})$; 6- $(-)$ epigallocatechin gallate (EGCG); 7- (-) epicatechin gallate (ECG) 




Figure 6: HPLC chromatogram of aerated black CTC tea at $278 \mathrm{~nm}$ spiked with internal standard guaiacol (2- methoxyphenol). Mixed standards at $278 \mathrm{~nm}$. Peaks: 1- gallic acid (GA); 2- (-) epigallocatechin (EGC); 3- caffeine (CA), $4-(+)$ catechin $(+C), 5-(-)$ epicatechin (EC); 6$(-)$ epigallocatechin gallate (EGCG); 7- (-) epicatechin gallate (ECG), 8(2- methoxyphenol)

\section{Development of Internal Standard Relative Response Factors (RRFS)}

A volume of $20 \mu \mathrm{L}$ of the mixed standard of GA, EGC, Caffeine, (+) C, EC, EGCG and ECG internal standard (2- 1000 $\mu \mathrm{g} / \mathrm{ml}$ ) was injected into the isocratic HPLC system. The result obtained was used to determine relative response factors, (table 2) for GA, caffeine and the catechins in relation to the internal standard using equation 1 .These factors were consequently used for Quantitation purposes and gave satisfactory levels of the biomolecules. The RRF can hence be reliably used in Quantitation of GA, EGC, caffeine, (+) C, EC, EGCG and ECG in different types of tea and tea based products.

$\mathrm{RRF}=\frac{\text { Weight of component } \times \text { Peak area }(\text { Internal Standard })}{\text { Peak area of component } \times \text { weight of internal standard }}$

Table 2: Relative response factors (RRFS) for GA, caffeine and the catechins in relation to guaiacol (2- methoxyphenol) internal standard

\begin{tabular}{|c|c|c|c|c|c|c|}
\hline Component & $\operatorname{Rep} 1$ & $\operatorname{Rep} 2$ & $\operatorname{Rep} 3$ & $\operatorname{Rep} 4$ & $\operatorname{Rep} 5$ & Mean \\
\hline GA & 0.29 & 0.28 & 0.29 & 0.28 & 0.28 & 0.29 \\
\hline EGC & 3.72 & 3.49 & 3.53 & 3.41 & 3.49 & 3.56 \\
\hline$(+) \mathrm{C}$ & 1.85 & 1.82 & 1.85 & 1.81 & 1.82 & 1.83 \\
\hline Caffeine & 0.35 & 0.36 & 0.37 & 0.35 & 0.36 & 0.36 \\
\hline EC & 1.55 & 1.55 & 1.56 & 1.52 & 1.54 & 1.55 \\
\hline EGCG & 0.82 & 0.81 & 0.82 & 0.8 & 0.8 & 0.81 \\
\hline ECG & 0.64 & 0.61 & 0.61 & 0.6 & 0.61 & 0.62 \\
\hline
\end{tabular}

\section{Validation of the Method}

Method validation is an important requirement for any package of information submitted to international regulatory agencies in support of new product marketing. Analytical methods should be validated, including methods published in relevant standard references. The suitability of all test methods used should always be verified under the actual conditions of use and should be well documented.

\section{Specificity of the Method}

The specificity of the method was investigated by injecting extracted placebo to demonstrate the absence coelution of analyte. The conditions for the method gave good specificity as there was no coelution in the mixed standard sample matrix, (figure 2) and both aerated (black) and non-aerated (green) tea extracts on being analyzed gave peaks that were specific with respect to each other. The trends did not change with repeated introduction of sample material (figures 3-6).

\section{Linearity, LOD and LOQ of the Method}

The linearity of the method was checked with standard solutions of GA, $(-)$ - EGC, caffeine, $(+)$ C, $(-)$ - EC, $(-)$ - EGCG, and $(-$ ) - ECG prepared at six concentrations in the concentration range of $2.5-500 \mu \mathrm{g} / \mathrm{mL}$. Three individually prepared replicates at each concentration were analyzed. The mean peak area of three injections and corresponding signal levels were used to generate equations for the regression line and correlation coefficients $\left(\mathrm{r}^{2}\right)$ for each of the standards. Limit of Detection (LOD) and limit of Quantitation (LOQ) were obtained from the standard deviation $(\sigma)$ of the blank response $(n=6)$ and slope (S) of calibration curves using the formula $3.3 \sigma / \mathrm{S}$ and $10 \sigma / \mathrm{S}$, respectively. All calibration curves yielded straight lines over a wide range and correlation coefficient greater $(>)$ than 0.99 . The results are as shown in table 3 . The concentration ranges taken were above the LOD and LOQ of the method and furthermore all types of teas under consideration here are not known to have their concentration outside the set limits [17]. The linearity data shows that the method meets the requirements of validation based on this parameter and hence fit for this kind of analysis. 
Table 3: Statistical data for regression plots, LOD and LOQ

\begin{tabular}{cccccc}
\hline Component & Linear range $(\boldsymbol{\mu g} / \mathbf{m L})$ & Equation for regression line & Correlation coefficient $\left(\mathbf{r}^{2}\right)$ & LOD & LOQ \\
\hline EGC & $25-400$ & $\mathrm{y}=0.00033 \mathrm{x}-0.0015$ & 0.9995 & 0.06 & 0.18 \\
$+\mathrm{C}$ & $25-250$ & $\mathrm{y}=0.011 \mathrm{x}-0.0162$ & 0.9969 & 0.09 & 0.27 \\
EC & $25-400$ & $\mathrm{y}=0.01361 \mathrm{x}-0.027$ & 0.997 & 0.02 & 0.18 \\
EGCG & $25-250$ & $\mathrm{y}=0.0225 \mathrm{x}-0.00098$ & 0.9999 & 0.16 & 0.48 \\
ECG & $25-250$ & $\mathrm{y}=0.0031 \mathrm{x}+0.042$ & 0.9969 & 0.11 \\
GA & $2.5-30$ & $\mathrm{y}=0.048 \mathrm{x}-0.0183$ & 0.9998 & 0.33 \\
Caffeine & $2.5-30$ & $\mathrm{y}=0.0441 \mathrm{x}-0.0058$ & 0.999 & 0.12 & 0.07 \\
\hline
\end{tabular}

\section{Precision of the Method}

The precision of the method was investigated by preparing one sample solution containing the target level of analyte. Ten replicates of this sample solution were analyzed with the retention time and peak area being recorded. The mean, standard deviation and relative standard deviation (RSD \%) were finally determined (table 4). Both Peak Areas (PA) and Retention Times (RT) for all the components gave low standard deviation from the respective means. In terms of relative standard deviation percentage (RSD \%) for the components the range was 0.241 $2.175 \%$ demonstrating that the method is fairly precise and can be used to get reproducible results.

\section{Accuracy of the Method}

Accuracy of the analytical method was determined by preparing quality control $(\mathrm{QC})$ materials of GA, (-)- ECG, (+)-C, caffeine, $(-)$ - EC, $(-)$ - EGCG, and (- )- EGC in a similar way to unknown samples at four predetermined concentration levels. The QC materials were repeatedly measured to determine the accuracy of the determinations. The mean recovery for the catechins ranged from 99.2 - 105.5\% while the recovery for gallic acid was $99.9 \%$ and that for caffeine was $105.3 \%$ (table 5). This demonstrated that the result found is satisfactory for the intended purpose and is adequate for routine analysis.

\section{Application of the Method}

Factory processed CTC non aerated green tea, CTC aerated black tea, orthodox non aerated green tea and orthodox aerated black tea from Kangaita tea factory of Kirinyaga County in Kenya were extraction for gallic acid, caffeine and catechins according to ISO 1405-2:2005(E) procedures. All samples were extracted in triplicate and analyzed using the developed improved isocratic method and the ISO 1405-2:2005(E) method for comparison purposes. Statistical analysis was carried out using SAS® V 9.1 for windows statistical software.

ANOVA was used to determine the means, coefficient of variation and Least Significance Difference (LSD) was used to separate means. The probability limit was set at $\mathrm{P} \leq 0.05$ significant level and the Standard Deviation (SD) done using the student t-test. Results of the parameter determined were expressed as a mean of the triplicate determination. Table 6 shows the statistics for method comparison for green CTC, green

Table 4: Precision test for GA, $(-)-$ EGC, Caffeine, $(+)$ C, , $(-)-$ EC, $(-)-$ EGCG, and $(-)$ - ECG

\begin{tabular}{|c|c|c|c|c|}
\hline Component & Parameter & Mean & SD & RSD \% \\
\hline \multirow{2}{*}{$\mathrm{GA}-(2.5 \mu \mathrm{g} / \mathrm{ml})$} & RT & 3.776 & 0.029 & 0.768 \\
\hline & PA & 113606 & 2471 & 2.175 \\
\hline \multirow{2}{*}{$\mathrm{EGC}-(50 \mu \mathrm{g} / \mathrm{ml})$} & RT & 4.084 & 0.031 & 0.759 \\
\hline & PA & 197057 & 474 & 0.241 \\
\hline \multirow{2}{*}{ Caff - $(2.5 \mu \mathrm{g} / \mathrm{ml})$} & RT & 4.516 & 0.054 & 1.196 \\
\hline & PA & 133484 & 785 & 0.588 \\
\hline \multirow{2}{*}{$+\mathrm{C}-(25 \mu \mathrm{g} / \mathrm{ml})$} & RT & 4.9 & 0.055 & 1.122 \\
\hline & PA & 326029 & 75975 & 1.833 \\
\hline \multirow{2}{*}{$\mathrm{EC}-(25 \mu \mathrm{g} / \mathrm{ml})$} & RT & 5.192 & 0.05 & 0.963 \\
\hline & PA & 430567 & 2541 & 0.59 \\
\hline \multirow{2}{*}{ EGCG - $(25 \mu \mathrm{g} / \mathrm{ml})$} & RT & 6.011 & 0.054 & 0.898 \\
\hline & PA & 627129 & 5796 & 0.924 \\
\hline \multirow{2}{*}{ ECG - $(25 \mu \mathrm{g} / \mathrm{ml})$} & RT & 9.121 & 0.087 & 0.954 \\
\hline & $\mathrm{PA}$ & 114368 & 574 & 0.502 \\
\hline
\end{tabular}


Table 5: Accuracy test for gallic acid, $(-)$ - ECG, $(+)$-catechin, caffeine, $(-)$ - EC, $(-)$ - EGCG, and $(-)$ - EGC

\begin{tabular}{|c|c|c|c|}
\hline Tea Component & Concentration $(\mu \mathrm{g} / \mathrm{ml})$ & Accuracy $(\mu \mathrm{g} / \mathrm{ml})$ & Recovery (\%) \\
\hline \multirow{4}{*}{ Gallic acid } & 2 & $2.10 \pm 0.50$ & 105.0 \\
\hline & 5 & $4.84 \pm 0.50$ & 96.8 \\
\hline & 10 & $9.79 \pm 0.50$ & 97.9 \\
\hline & 15 & $14.66 \pm 0.50$ & 97.7 \\
\hline \multirow{4}{*}{ Epigallocatechin } & 25 & $24.32 \pm 0.90$ & 97.3 \\
\hline & 50 & $50.89 \pm 0.20$ & 101.8 \\
\hline & 100 & $98.70 \pm 0.60$ & 98.7 \\
\hline & 150 & $148.79 \pm 0.80$ & 99.2 \\
\hline \multirow{4}{*}{+ Catechin } & 25 & $26.81 \pm 0.50$ & 107.2 \\
\hline & 50 & $50.15 \pm 0.50$ & 100.2 \\
\hline & 100 & $99.39 \pm 0.50$ & 99.4 \\
\hline & 150 & $149.02 \pm 0.50$ & 99.3 \\
\hline \multirow{4}{*}{ Caffeine } & 2 & $2.04 \pm 0.90$ & 102.0 \\
\hline & 5 & $5.55 \pm 0.70$ & 111.0 \\
\hline & 10 & $10.35 \pm 0.50$ & 103.5 \\
\hline & 15 & $14.95 \pm 0.90$ & 99.7 \\
\hline \multirow{4}{*}{ Epicatechin } & 25 & $26.53 \pm 0.90$ & 106.1 \\
\hline & 50 & $48.98 \pm 0.80$ & 98 \\
\hline & 100 & $102.35 \pm 0.70$ & 102.4 \\
\hline & 150 & $148.83 \pm 0.90$ & 99.2 \\
\hline \multirow{4}{*}{ Epigallocatechin gallate } & 25 & $25.23 \pm 0.40$ & 100.9 \\
\hline & 50 & $50.10 \pm 0.90$ & 100.2 \\
\hline & 100 & $103.71 \pm 0.82$ & 103.7 \\
\hline & 150 & $151.52 \pm 0.60$ & 101.0 \\
\hline \multirow{4}{*}{ Epicatechin gallate } & 25 & $25.32 \pm 0.50$ & 101.3 \\
\hline & 50 & $49.37 \pm 0.90$ & 98.7 \\
\hline & 100 & $100.97 \pm 0.70$ & 101.0 \\
\hline & 150 & $152.39 \pm 0.70$ & 101.6 \\
\hline
\end{tabular}

Table 6: Method comparison for levels of GA, EGC, Caffeine, +C, EC, EGCG, ECG and total catechin in the different types of tea

\begin{tabular}{|c|c|c|c|c|c|}
\hline Tea type & Component & & & ANOVA & \\
\hline \multirow{9}{*}{ Green CTC } & & New method & ISO method & CV & LSD \\
\hline & GA & $0.61^{\mathrm{a}} \pm 0.03$ & $0.63^{\mathrm{a}} \pm 0.20$ & 12.8 & 0.28 \\
\hline & EGC & $5.76^{\mathrm{a}} \pm 0.61$ & $5.86^{\mathrm{a}} \pm 0.50$ & 5.8 & 1.10 \\
\hline & Caffeine & $3.52^{\mathrm{a}} \pm 0.24$ & $3.73^{\mathrm{a}} \pm 0.21$ & 3.8 & 0.49 \\
\hline & $+\mathrm{C}$ & $0.56^{\mathrm{a}} \pm 0.03$ & $0.53^{\mathrm{a}} \pm 0.03$ & 7.3 & 0.14 \\
\hline & $\mathrm{EC}$ & $1.97^{\mathrm{a}} \pm 0.24$ & $1.36^{\mathrm{a}} \pm 0.19$ & 14.8 & 0.86 \\
\hline & EGCG & $8.86^{\mathrm{a}} \pm 1.29$ & $8.71^{\mathrm{a}} \pm 0.43$ & 13.8 & 4.24 \\
\hline & ECG & $2.31^{\mathrm{a}} \pm 0.37$ & $2.29^{\mathrm{a}} \pm 0.19$ & 8.7 & 0.70 \\
\hline & Total catechin & $19.46^{\mathrm{a}} \pm 1.27$ & $18.74^{\mathrm{a}} \pm 1.02$ & 8.4 & 5.63 \\
\hline
\end{tabular}




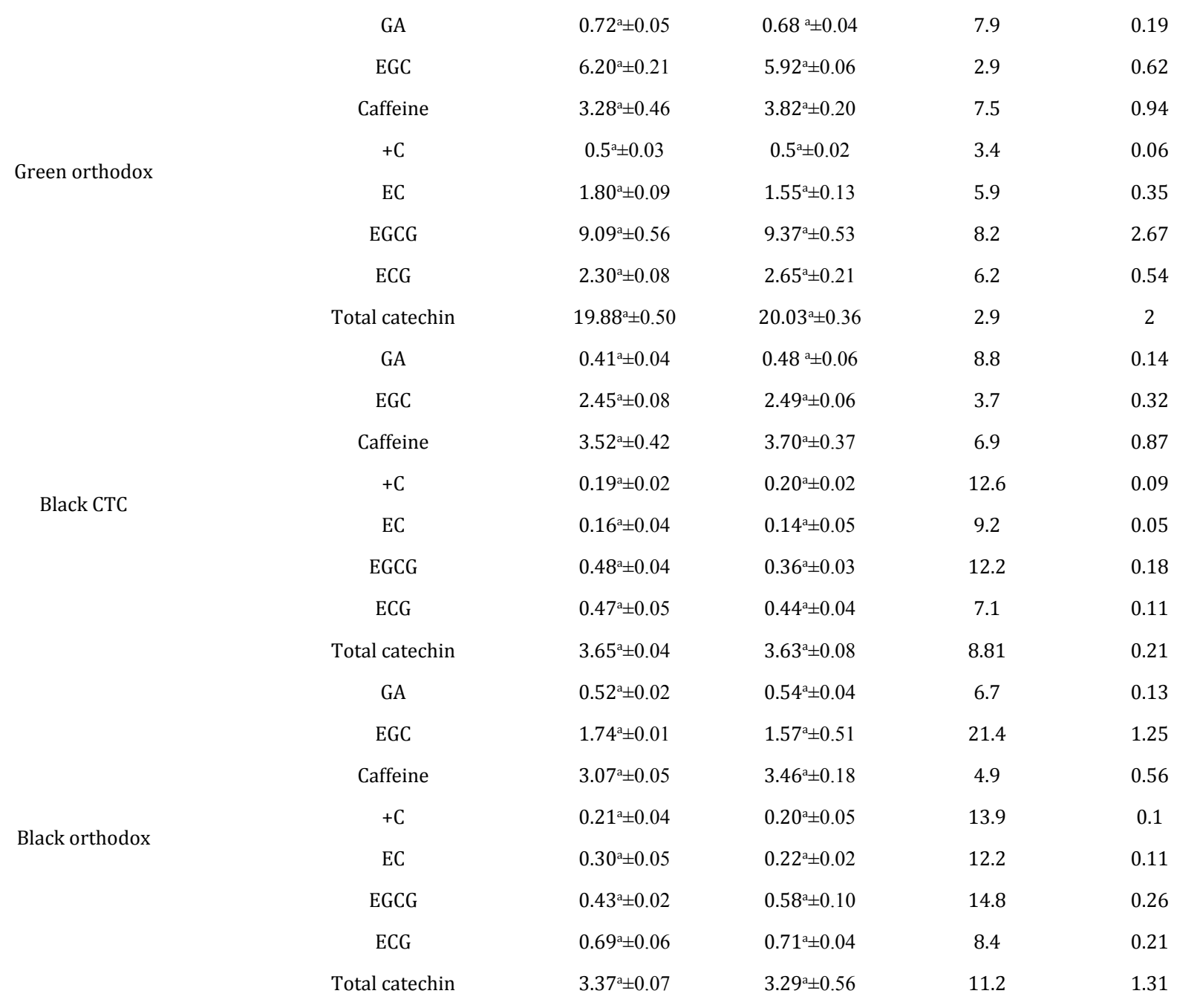

Means with the same letter in the same column are not statistically significant

orthodox, black CTC, and black orthodox teas. All the biomolecules of interest in this study - GA, EGC, +C, EC, EGCG, ECG and caffeine were present in all the teas. In general, both green CTC and green orthodox teas contained significantly higher concentrations of catechins than the black teas whereas the contents of GA and caffeine remained constant. The differences can be attributed to the manufacture process where catechins combine with the biological enzyme polyphenol oxidase and with the help of the atmospheric oxygen oxidize to theaflavins and thearubigins. GA and caffeine are not affected by the oxidative process of manufacture and hence remain relatively constant during the oxidative degradation of the catechins and other phenols. All these facts were well demonstrated by the conditions set in the newly developed method and the conditions of the ISO 1405 2:2005(E) method which is widely used in determination of tea biomolecules. Additionally, all parameters of measurement did not show significant differences between the two methods and hence the two methods are in close agreement.

\section{Conclusions}

Tea is known for its complex mixture of phytochemicals. Polyphenols, catechins, caffeine and gallic acid have lately elicited attention in line with the health benefits associated with these biomolecules. Tea value added products are increasingly becoming common in the local market and dietary polyphenols comprise a wide range of aromatic compounds which can easily be sourced from tea. The growing importance of the commonly known tea types, specialty developed types and tea value added products necessitated the development of a sensitive, fast, cost effective and accurate HPLC method. A simple isocratic HPLC method that can perform qualitative and quantitative determination of gallic acid, $(+)$ - catechin, $(-)$ - EC, $(-)$ - ECG, $(-$ ) - EGCG, $(-)$ - EGC and caffeine in tea and tea related products has been developed. The method has proved to be specific and precise and has shown good performance with the column of choice. The total elution time is impressively short (10minutes) and with the internal standard being incorporated analysis can be achieved in 12.5 minutes compared to the 42 minutes of the current ISO 1405-2:2005(E) method. 


\section{References}

1. Adam, A A E M. Isolation, Characterization and Biological Activity of Flavonoids from CordiaSinensis and Acacia Orefota (Doctoral dissertation, Sudan University of Science and Technology), 2017.

2. Amerine MA, Pangborn, RM, Roessler, EB. Principles of sensory evaluation of food. Elsevier (2013).

3. Ananingsih VK, Sharma A, Zhou W. Green tea catechins during food processing and storage: a review on stability and detection. Food Research International. 2013;50(2):469-479.

4. Babu Sukumaran Santhosh, Vakayil K Praveen, Ayyappanpillai Ajayaghosh. Functional $\pi$-gelators and their applications. Chemical reviews. 2014;114(4):1973-2129.

5. Chacko SM, Thambi PT, Kuttan R, Nishigaki I. Beneficial effects of green tea: a literature review. Chin Med. 2010;5:13. doi: 10.1186/1749-8546-5-13

6. Dalluge JJ, Nelson BC. Determination of tea catechins. Journal of Chromatography A. 2000;881(1-2):411-424.

7. Del Rio D, Rodriguez-Mateos A, Spencer JP, Tognolini M, Borges G, Crozier A. (2013). Dietary (poly) phenolics in human health: structures, bioavailability, and evidence of protective effects against chronic diseases. Antioxid Redox Signal. 2013;18(14):18181892.

8. Dias TR1, Alves MG, Tomás GD, Socorro S, Silva BM, Oliveira PF. White tea as a promising antioxidant medium additive for sperm storage at room temperature: a comparative study with green tea. J Agric Food Chem. 2014;62(3):608-617. doi: 10.1021/jf4049462

9. Farhat G, Drummond S, Fyfe L, Al-Dujaili EA. Dark chocolate: an obesity paradox or a culprit for weight gain? Phytother Res. 2014;28(6):791-797. doi: 10.1002/ptr.5062

10. Food and Drug administration, Guidance for industry: bioanalytical method validation 2001.

11. Hamilton RJ, Sewell PA. (1982). Equipment. In Introduction to high performance liquid chromatography (pp. 42-79). Springer, Dordrecht.

12. Ignat I, Volf, Popa VI. A critical review of methods for characterization of polyphenolic compounds in fruits and vegetables. Food chemistry. 2011;126(4):1821-1835.

13.Joubert E, \& de Beer D. Rooibos (Aspalathus linearis) beyond the farm gate: From herbal tea to potential phytopharmaceutical. South African Journal of Botany. 2011;77(4): 869-886.

14. Karschner EL. (2010). Pharmacodynamic and Pharmacokinetic Characterization of Sativex and Oral THC (Doctoral dissertation, University of Maryland, Baltimore).

15. Koech K, Wachira F, Ngure R, Wanyoko J, Bii C, Karori S. (2013). Antibacterial and Synergistic Activity of Different Tea Crude Extracts against Antibiotic Resistant S. aureus, E. coli and a Clinical Isolate of S. typhi. Science Journal of Microbiology. 2013;2013:115. doi: $10.7237 / \mathrm{sjmb} / 115$

16. Kuriyama S, Shimazu T, Ohmori K, Kikuchi N, Nakaya N, Nishino Y. Green tea consumption and mortality due to cardiovascular disease, cancer, and all causes in Japan: the Ohsaki study. Jama. 2006;296(10):1255-1265.
17. Li DW, Zhu M, Shao YD, Shen Z, Weng CC, Yan WD. Determination and quality evaluation of green tea extracts through qualitative and quantitative analysis of multi-components by single marker (QAMS). Food Chem. 2016;197: 1112-1120. doi: 10.1016/j. foodchem.2015.11.101

18. Li Y, Guo C, Yang J, Wei J, Xu J, Cheng S. Evaluation of antioxidant properties of pomegranate peel extract in comparison with pomegranate pulp extract. Food chemistry. 2006;96(2): 254-260.

19. Mangenya TM. (2016). Assessment of Catechins and other Polyphenols as Parameters of Tea Quality in selected Ecological Zones in Kenya (Doctoral dissertation, Jomo Kenyatta University of Agriculture and Technology).

20. Martin LC. (2011). Tea: the drink that changed the world. Tuttle Publishing.

21. Meydani M, Hasan ST. (2010). Dietary polyphenols and obesity. Nutrients. 2010;2(7):737-751. doi: 10.3390/nu2070737

22.MarinaNaldi, JessicaFiori, RobertoGotti, AuréliePériat, JeanLucVeuthey, DavyGuillarme (2014). UHPLC determination of catechins for the quality control of green tea. Journal of pharmaceutical and biomedical analysis. 2014;88:307-314.

23. Nile SH, Park SW. Edible berries: Bioactive components and their effect on human health. Nutrition. 2014;30(2):134-144. doi: 10.1016/j.nut.2013.04.007

24. Mutshekwa N. (2017). Effect of time-based hot air drying method on chemical composition of jatropha zeyheir tea (Doctoral dissertation, University of Limpopo).

25. Ochanda SO, Wanyoko JK, Faraj AK, Onyango CA, Ruto HK. Effects of Tea (Camellia sinensis) Phytochemicals on the Yoghurt Cultures (Lactobacillus bulgaricus and Streptococcus thermophilus) During Development and Storage of Tea Fortified Yoghurts. Journal of Food Research. 2015;4(4):59.

26. Perumalla AVS, Hettiarachchy NS. Green tea and grape seed extracts-Potential applications in food safety and quality. Food Research International. 2011;44(4):827-839.

27. Piljac-Žegarac J, Šamec, D, \& Piljac A. Herbal teas: A focus on antioxidant properties. In Tea in Health and Disease Prevention. 2013;129-140.

28. Rahim AA, Nofrizal S, Saad B. Rapid tea catechins and caffeine determination by HPLC using microwave- assisted extraction and silica monolithic column. Food Chem. 2014;147:262-268. doi: 10.1016/j.foodchem.2013.09

29. Saito ST, Welzel A, Suyenaga ES, Bueno F. A method for fast determination of epigallocatechin gallate (EGCG), epicatechin (EC), catechin (C) and caffeine (CAF) in green tea using HPLC. Food Science and Technology. 2006;26(2):394-400.

30.Sang S, Lambert JD, Ho, CT, Yang CS. The chemistry and biotransformation of tea constituents. Pharmacol Res. 2011;64(2):87-99. doi: 10.1016/j.phrs.2011.02.007

31. Sliwinska M, Wisniewska P, Dymerski T, Namiesnik J, Wardencki W. Food analysis using artificial senses. Journal of agricultural and food chemistry. 2014;62(7):1423-1448.

32.Swartz ME, \& Krull IS. (1997). Analytical method development and validation: CRC Press. 